\title{
PLURALISMO JURÍDICO E NECROPOLÍTICA EM "BACURAU": O CINEMA COMO MANIFESTAÇÃO DE FENÔMENOS SOCIOJURÍDICOS
}

\author{
Raissa Rayanne Gentil de Medeiros ${ }^{1}$ \\ Jessica de Jesus Mota ${ }^{2}$ \\ Kauê Suptitz
}

\section{RESUMO}

O longa "Bacurau" retrata a realidade de uma cidade no interior de Pernambuco marcada pelo abandono de políticas públicas, com um povo que conta somente com sua união e sua força de trabalho para superar as adversidades de uma vida pautada pela escassez. A partir disso, questiona-se: como "Bacurau" retrata situações de pluralismo jurídico e expõe a necropolítica presentes no neocolonialismo que perpassa a realidade brasileira? Neste trabalho, foi realizada uma revisão bibliográfica a partir dos conceitos de pluralismo jurídico e necropolítica, bem como uma análise do filme para compreender como a película brasileira retrata as categorias estudadas.

Palavras-chave: Pluralismo jurídico; Necropolítica; Direito e cinema; Neocolonialismo; Bacurau.

\section{LEGAL PLURALISM AND NECROPOLITICS IN "BACURAU": CINEMA AS A MANIFESTATION OF SOCIO-LEGAL PHENOMENA}

\begin{abstract}
The film "Bacurau" portrays a city in the interior of Pernambuco marked by the abandonment of public policies, where the people rely only on its union and its workforce to overcome the adversities of a life marked by scarcity. From this, the question arises: how does "Bacurau" portray situations of legal pluralism and expose the necropolitics present in neocolonialism that permeates the brazilian reality? In this work, a bibliographic review was carried out based on the concepts of legal pluralism and necropolitics. Also, the film was analyzed as a way to understand how the brazilian film portrays the categories studied.
\end{abstract}

Keywords: Legal pluralism; Necropolitics; Law and cinema; Neocolonialism; Bacurau.

\section{INTRODUÇÃO}

Na contemporaneidade, tem-se pensado o Direito para além da legislação formal, debruçando-se sobre as realidades fáticas e jurídicas retratadas em manifestações culturais, o

\footnotetext{
${ }^{1}$ Mestranda em Direito no Programa de Pós-Graduação em Direito da Universidade Federal do Rio Grande do Sul (UFRGS). Graduada em Direito pela Universidade Federal do Rio Grande do Norte (UFRN). Bolsista pela CAPES. Email: raissa.medeiros@hotmail.com

${ }^{2}$ Mestranda em Direito no Programa de Pós-Graduação em Direito da Universidade Federal do Rio Grande do Sul (UFRGS). Graduada em Direito pela Universidade Federal de Pelotas (UFPEL). Bolsista pela CAPES. Email: jejemota01@gmail.com

${ }^{3}$ Mestrando em Direito no Programa de Pós-Graduação em Direito da Universidade Federal do Rio Grande do Sul (UFRGS). Graduado em Ciências Jurídicas e Sociais pela Pontifícia Universidade Católica do Rio Grande do Sul (PUC/RS). Advogado. E-mail: skaue@live.com
} 
que corroborou para o desenvolvimento de estudos sobre "Direito e Arte", "Direito e Literatura" e "Direito e Cinema". Ainda muito incipiente no Brasil, os estudos sobre "Direito e Cinema" tem sido uma potente ferramenta para expor e denunciar importantes fenômenos sociojurídicos que devem ser analisados pela academia, por estudantes e profissionais do Direito (MARTINEZ, 2015).

Desse modo, o cinema nacional ganha notoriedade com a produção de filmes e documentários que denunciam situações de violência no país, concentrando-se em retratar as mazelas da sociedade brasileira e a precarização da vida daqueles que vivem em meios violentos ou extremamente carentes de estruturas materiais. Logo, numa sociedade marcada por desigualdades e violências, "o cinema tem um papel simbólico-político importante a cumprir" (SELIGMANN-SILVA, 2008, p. 105).

É neste cenário que se insere o longa brasileiro Bacurau (2019), dirigido por Kleber Mendonça Filho, e premiado no Festival de Cannes ${ }^{4}$ no ano de seu lançamento. O filme retrata a realidade de Bacurau, uma cidade no interior de Pernambuco, marcada pelo abandono de políticas públicas, com um povo que conta somente com sua força de trabalho e união para superar as adversidades de uma vida pautada pela escassez. Logo, os bacurauenses criam seus próprios mecanismos de defesa e administração de recursos que garantem sua sobrevivência e resistência, evidenciando uma situação de pluralismo jurídico (AQUINO; LOPES, 2020).

Desse modo, onde o Estado não chega acaba por tornar-se local ideal para as políticas de morte presentes no neocolonialismo, perpetuadas pelo norte global e que atingem o sul global, historicamente negligenciado. Nesse sentido, no momento em que o filme Bacurau (2019) retrata o fato de que um grupo de estadunidenses propõe-se a planejar e executar um massacre numa cidade no interior de Pernambuco por esporte, visto que estão impregnados com uma ideologia racista que separa e categoriza, inclusive, brasileiros do sul e sudeste, daqueles do norte e nordeste, evidencia-se a utilização de uma necropolítica, em que se decide, quase que literalmente, quem vai morrer e quem vai viver. A necropolítica é ferramenta importante quando se trata do neocolonialismo dos países do sul global e corrobora para internalização de condutas e medidas permeadas pelo autoritarismo e políticas coronelistas, especialmente, quando se trata da realidade do nordeste brasileiro.

\footnotetext{
${ }^{4}$ Disponível em: <https://g1.globo.com/pop-arte/cinema/noticia/2019/05/25/bacurau-vence-premio-do-juri-nofestival-de-cannes.ghtml. Acesso em: 11 de abril de 2021> Acesso em: 06. abril 2021.
} 
A partir dos fatores expostos acima, questiona-se: Como o filme brasileiro Bacurau (2019) retrata situações de pluralismo jurídico e expõe a necropolítica presentes no neocolonialismo que perpassa a realidade brasileira? Para responder esse questionamento, num primeiro momento, foi realizada uma revisão de literatura acerca do conceito de pluralismo jurídico, a partir dos estudos de Antônio Carlos Wolkmer (2001) e Boaventura de Souza Santos (2018), aliadas as categorias de normas sociais, jurídicas e ideológicas elaboradas por Lucas Pizzolatto Konzen (2013). Após, analisa-se o conceito de necropolítica de Achille Mbembe (2018) no contexto do neocolonialismo dos países do sul global e as consequências disso em políticas coronelistas que marcam a realidade do nordeste brasileiro. Por fim, a partir dos marcos teóricos supracitados, busca-se fazer uma análise do filme, com o fito de entender como a película brasileira retrata as categorias estudadas.

Utiliza-se neste estudo o método de abordagem indutivo, de caráter qualitativo, aliados às técnicas de revisão bibliográfica, e a análise de uma produção cinematográfica, baseada nos estudos sobre Direito e Arte, em diálogo com os marcos teóricos do pluralismo jurídico e da necropolítica. Evidencia-se, assim, como os fenômenos sociojurídicos podem se manifestar através da arte.

\section{PLURALISMO JURÍDICO: NORMAS PARA ALÉM DO ESTADO}

O pluralismo jurídico, enquanto um fenômeno social que se desenrola por diferentes campos das atividades humanas, é muito complexo para ser definido sem correr o risco de esquecer alguma de suas possibilidades. Por isso, ele pode ser pensado sob várias perspectivas e a partir de uma noção mais ampla de pluralismo ou de pluralidades. Dessa maneira, partindo de uma dimensão filosófica, pode-se entender o pluralismo como uma formulação teórica e doutrinária que indica a existência de mais de uma realidade, de uma variedade de formas de ação prática e da diversidade de campos sociais com particularidade própria, ou seja, o pluralismo envolve o conjunto de fenômenos autônomos e elementos heterogêneos que não se reduzem entre si (WOLKMER, 2001, p. 171-172).

Essa reflexão atinge as práticas sociais, que indiscutivelmente se manifestam em relações plurais em quaisquer sociedades, de acordo com diferentes cenários, interesses e grupos culturais ou socioeconômicos envolvidos. Assim, essas práticas plurais se desenvolvem no campo da política, da economia, da arte, das atividades econômicas e produtivistas, do esporte e das práticas de lazer e de filosofias de vida pessoais, o que é 
evidente considerando que diferentes indivíduos ou grupos comunitários são movidos por dinâmicas próprias e específicas (FRANÇA, 2018, p. 17)

Boaventura de Sousa Santos (2018, p. 01) assinala que:

\begin{abstract}
Existe uma situação de pluralismo jurídico sempre que no mesmo espaço geopolítico vigoram (oficialmente ou não) mais de uma ordem jurídica. Esta pluralidade normativa pode ter uma fundamentação econômica, rácica, profissional ou outra; pode corresponder a um período de ruptura social como, por exemplo, um período de transformação revolucionária; ou pode ainda resultar (...) da conformação específica do conflito de classes numa área determinada da reprodução social (...).
\end{abstract}

Esse fenômeno geralmente ocorre em razão do fracasso do Estado moderno em se manter como instituição única de regulação social e solução de conflitos. Nessa conjuntura, "no vazio deixado pelo Estado, surgem mecanismos alternativos de resolução de conflitos" (CARVALHO, 2013, p. 21). Embora o reconhecimento do pluralismo jurídico enquanto fato social seja contestatório no tocante à ordem jurídica vigente, essas práticas ocorrem na realidade concreta, regulando as relações sociais, de forma clara e inconteste (WOLKMER, 2001, p. 156).

Assim, ao contrário do que busca a filosofia política liberal e a ciência do direito que sobre ela se constituiu, estão presentes na sociedade não apenas uma, mas várias formas de direito ou modos de juridicidade. O direito advindo do Estado, tido como "oficial" vez que está nos códigos e é legislado pelo governo ou pelo parlamento, se trata somente de uma dessas formas. Ressalte-se, ainda, que essas diversas formas variam no que se refere aos campos da ação social ou aos grupos sociais que regulam, assim como a sua durabilidade, à maneira como tentam prevenir os conflitos individuais ou sociais e os resolvem sempre que ocorrem, e também quanto aos mecanismos de reprodução da legalidade e distribuição ou sonegação do conhecimento jurídico (SANTOS, 1988, p. 147-148).

Desta forma, o pluralismo se anuncia em oposição ao chamado "monismo jurídico", que se firma doravante a ideia de que o direito estatal é auto suficiente e auto legitimado. $\mathrm{O}$ monismo acaba por descolar o meio jurídico da realidade social concreta, tornando-o um ente distante e abstrato (CARVALHO, 2013, p. 15). Ironicamente, é justamente em razão deste distanciamento que diversos corpos sociais, não se sentindo representados ou atendidos pelas instituições estatais, começam a desenvolver, mesmo que involuntariamente, organizações próprias dotadas de juridicidade e caráter administrativo, buscando solucionar seus conflitos e garantir, de alguma maneira que seja, a efetividade de direitos e seguridades mal atendidos pelo aparato estatal (FRANÇA, 2018, p. 18). 
Essas normas assumem formas distintas, podendo ser orais, escritas em leis, escritas em estatutos informais, internalizações culturais. Também podem ocorrer em diversas escalas, como é o caso de uma casa, de um ambiente de trabalho, uma comunidade, uma região do mundo, o espaço de um transporte público. Todas elas, de alguma forma, regulam relações sociais e é por isso que o pluralismo jurídico acaba por ser um dos principais pressupostos do campo da sociologia do direito.

O pluralismo, então, antes de ser uma formulação teórica, é um fato e para além das diferentes propostas teóricas que categorizam esse fenômeno, ele pode ser observado empiricamente. Sobre as categorias de normas, Lucas Pizzolatto Konzen (2013) entende que elas se dividem em três tipos: jurídicas (ou estatais), sociais e ideológicas.

As normas jurídicas são mais complexas, elaboradas e o tipo "mais visível" de normas, em razão da forte e generalizada crença no Direito positivado na sociedade ocidental contemporânea. Elas consistem em um conjunto de declarações normativas formalizadas, articuladas através de textos estatutários, decisões judiciais etc e estão ligadas às instituições, que são atores sociais de natureza fictícia constituída por um conjunto de normas jurídicas. As normas estatais são reproduzidas em uma arena particular, o sistema jurídico, que se constitui não apenas dos tribunais, mas também dos órgãos administrativos. Konzen explica, ainda, que os mecanismos para a aplicação dessa categoria de normas são burocráticos, claramente definidos e que as sanções contra violações das mesmas são impostas aos indivíduos pelas instituições, inclusive pela violência coercitiva do Estado (KONZEN, 2013, p. 80).

As normas sociais (KONZEN, 2013, p. 81) correspondem às normas informais, não institucionalizadas, que são reproduzidas cotidianamente. Essas normas dizem respeito às relações cotidianas das pessoas em qualquer tipo de comunidade unida: seja a família, o local de trabalho, a vizinhança. Konzen (2013) destaca que os indivíduos tendem a seguir certas normas estabelecidas dentro das comunidades ou associações às quais se identificam, sabendo que suas ações estão sujeitas à aprovação ou desaprovação de outros membros, vez que as comunidades inevitavelmente desenvolvem um conjunto de normas para orientar o comportamento daqueles que a ela pertencem.

Assim, uma vez que existem diferentes comunidades na sociedade, existem também diversas normas que se enquadram no conceito amplo de normas sociais: normas familiares, normas profissionais, normas religiosas e assim por diante. As normas sociais não são aplicadas pela força coercitiva do Estado ou por outras instituições sociais, as sanções 
normalmente afetam apenas um indivíduo ou um pequeno grupo de indivíduos dentro da comunidade e violações graves das normas sociais podem levar a uma rejeição ou exclusão do membro do grupo (KONZEN, 2013, p. 81).

Por fim, as normas ideológicas (KONZEN, 2013, p. 81) são menos elaboradas e relativamente invisíveis, consistindo em normas mais vagas e indeterminadas em seu caráter, mas extremamente difundidas na sociedade. Embora não estejam escritas, seu conteúdo normativo pode de alguma forma ser comunicado visualmente e articulado em termos explícitos.

Esse conceito de normas ideológicas é, também, uma ferramenta operacional que pode ser usada para apreender a dimensão normativa das ideologias, ou seja, a maneira pela qual as ideologias influenciam a ação normativa na sociedade. Normas deste tipo expressam os interesses de grupos da sociedade, mas se manifestam como um conjunto abrangente de ideais normativos propostos por grupos sociais à sociedade como um todo, não sendo reproduzidas associadas a uma instituição social específica. Ao contrário, são normas informais e não institucionalizadas que são reproduzidas na arena da cultura de massa e do conhecimento técnico (KONZEN, 2013, p. 81).

\section{NECROPOLÍTICA, NEOCOLONIALISMO E POLÍTICAS LOCAIS CORONELISTAS}

Ao pensar sobre o filme Bacurau (2019), localiza-se a cidade do interior de Pernambuco, no nordeste brasileiro, num país sul americano, colonizado e marcado por políticas de exploração e violência decorrentes de estratégias neocolonialistas. Essa violência é decorrente de políticas liberais e neoliberais, em que se manifesta o chamado biopoder, conceituado por Michel Foucault (2008) como sendo um domínio de vida sobre o qual o poder estabeleceu seu controle, perspectiva que atravessa os países do sul global (FOUCAULT, 2008). Contudo, o conceito de biopoder torna-se insuficiente para dar conta das formas contemporâneas de submissão da vida ao poder da morte, tendo em vista as peculiaridades de novas formas de violência e de guerra (MBEMBE, 2018).

Desta feita, Achille Mbembe (2018) propõe a noção de necropolítica e de necropoder para dar conta das diversas maneiras pelas quais, na contemporaneidade, são dispostas novas formas de guerra com o objetivo de destruir certas pessoas e criar "mundos de morte". Esses 
mundos são novas formas de existência social, nas quais populações são submetidas a condições de vida que lhes conferem o estado de "mortos-vivos".

Diante disso, inicialmente, o autor expõe sobre a necessidade de compreender a política como sendo, a grosso modo, a morte que vive uma vida humana (MBEMBE, 2018). Isso ocorre, pois, as experiências de destruição humana contemporâneas sugerem que “ (...) é possível desenvolver uma leitura da política, da soberania e do sujeito, diferente daquela que herdamos do discurso filosófico da modernidade" (MBEMBE, 2018, p. 11). Assim, tornar-se sujeito significa sustentar o trabalho da morte.

Após, o autor trata da soberania expressa predominantemente como o direito de matar, fazendo relação entre a questão de biopoder e a chamada inimizade, isto é, a figura ficcional do inimigo. Em especial, dentro do contexto de um estado de exceção (MBEMBE, 2018). Esse processo e configuração do que é o inimigo foi facilitado pelos estereótipos racistas e pelo florescimento de um racismo de classe que corrobora para uma visão do um conquistador de que o outro é o selvagem e, de certo modo, o inimigo (MBEMBE, 2018, p. 21).

Nesse sentido, quando se trata das localidades do sul global, o autor dispõe que as colônias acabam sendo zonas em que a guerra e a desordem prevalece, cujos controles e garantias de ordem judicial podem ser suspensos. Assim, trata-se de uma zona em que a violência do estado de exceção, supostamente, opera a serviço de pauta até mesmo "civilizatória". Logo:

Por todas essas razões, o direito soberano de matar não está sujeito a qualquer regra nas colônias. Lá, o soberano pode matar a qualquer momento ou de qualquer maneira. A guerra colonial não está sujeita a normas legais e institucionais. Não é uma atividade codificada legalmente. Em vez disso, o terror colonial se entrelaça constantemente com um imaginário colonialista, caracterizado por terras selvagens, morte e ficções que criam o efeito de verdade. (MBEMBE, 2018, p. 36).

Outrossim, a soberania acaba por ser a capacidade de definir quem importa e quem não importa, quem seria descartável ou não (MBEMBE, 2018). Dentro deste contexto, estabelece-se estratégias e técnicas que visam acabar com os recursos daqueles que seriam os inimigos ou, numa perspectiva ainda mais colonial, os "selvagens". Trata-se de uma verdadeira sabotagem da rede de infraestrutura social e urbana do inimigo, o que permite uma completa apropriação dos recursos de terra, água e espaço aéreo, por exemplo. Tais técnicas de inabilitação do inimigo é a da chamada terra arrasada que consiste em: 
(...) demolir casas e cidades; desenraizar as oliveiras; crivar de tiros tanques dc água; bombardear e obstruir comunicações eletrônicas; escavar estradas; destruir transformadores de energia elétrica; arrasar pistas de aeroporto; desabilitar os transmissores de rádio e televisão; esmagar computadores; saquear símbolos culturais e político-burocráticos do Proto-Estado Palestino; saquear equipamentos médicos (MBEMBE, 2018, p. 47).

Essas técnicas são uma tentativa de inabilitação do inimigo, ou seja, a aplicação de uma medida de terra arrasada. Por inimigo, entende-se todo aquele outro que é desumanizado e posto numa classificação de hierarquia social.

Contudo, nota-se que por colonialidade compreende-se, a partir de uma análise histórica, a expansão de poder dos países do continente Europeu sobre o Novo Mundo e o continente africano. Incluiria-se assim até mesmo os Estados Unidos da América, antiga colônia inglesa. Ainda que em similar contexto de colônia, os Estados Unidos da América difere do Brasil ao desenvolver, por meio do imperialismo, a posição de superpotência mundial e econômica. Desse modo, deixa o papel de país colonizado e explorado para tornarse colonizador e explorador (BALLESTRIN, 2017).

Por essa razão, visualiza-se, na contemporaneidade, os Estados Unidos da América como grande perpetuador de violências e práticas neocoloniais, responsáveis por uma submissão dos países latino-americanos. Nesse contexto, insere-se o Brasil, que de início, baseia-se em políticas pautadas pelas ordens europeias e, posteriormente, passa a obedecer os Estados Unidos da América, imitando suas práticas políticas e econômicas. Os invasores norte-americanos do filme têm enraizado o pensamento de hierarquia social, baseado no racismo de classe, cuja visão do conquistador é de que o outro é o selvagem, sendo assim o inimigo.

Para além disso, Bacurau localiza-se em uma região do nordeste brasileiro, marcada por políticas coronelistas. De acordo com Carvalho (1987), não há um conceito claro e unívoco sobre o coronelismo. O que temos são descrições, mais ou menos detalhadas, de uma forma específica do poder, historicamente configurada no Brasil, e que recebe o nome de coronelismo. Tal fenômeno perpassa o cenário histórico brasileiro desde a Primeira República, em especial, na política regional nordestina.

Contudo, a obra intitulada "Coronelismo, enxada e voto", de Victor Nunes Leal (1984), publicada a primeira vez em 1949, trouxe importantes contribuições sobre as situações históricas que hoje facilmente apontamos como coronelismo. A obra desde seu nascimento passou a ser um dos clássicos da literatura política e aponta que analisar o 
coronelismo não é analisar um fenômeno simples, mas sim um processo político complexo, cujos efeitos perpetuam na contemporaneidade e, a partir disso, constrói-se conceitos mais atuais como o "neocoronelismo",

Desse modo, Leal (1984) acredita que o conceito de coronelismo supera o entendimento de que esse fenômeno é, em verdade, o resultado de uma estrutura econômica e social inadequada, bem como afasta a compreensão ainda reduzida de ele seja a manifestação da sobrevivência do poder privado, que constituiu fenômeno típico de nossa história colonial. Partindo-se dessa premissa, é possível entender por coronelismo um fenômeno que é, sobretudo, um compromisso em que se troca proveitos entre o poder público e a influência social dos chefes locais proprietários de terras. Logo, não se pode compreender o fenômeno do coronelismo, sem dimensionar e analisar a própria estrutura agrária brasileira (LEAL, 1984).

Nessa esteira, destaca-se que as manifestações de poder privado ainda são muito visíveis, especialmente, no interior do Brasil, visto que foram alimentados pelo próprio poder público que no momento histórico de um regime representativo, com sufrágio amplo, não abria mão do eleitorado rural (LEAL, 1984). Logo, Leal (1984) aduz que esse compromisso fundamental resulta no que seria considerado por ele como características secundárias do sistema coronelista, quais sejam: o "mandonismo", o "filhotismo", o falseamento do voto, a desorganização dos serviços públicos locais.

Tais categorias de análise servem como guia no percurso histórico e teórico do autor supracitado. Num primeiro momento, ao abordar sobre o que seria o mandonismo, é possível inferir que é fator importante quando se trata da figura do coronel, mas que não pode ser reduzida como sinônimo de coronelismo. O mandonismo local faria parte de um sistema maior e estaria diretamente ligado ao que se chama de filhotismo, esse é, portanto, outra face do mandonismo que convoca agregados "para a 'gamela' municipal, e, de outro lado, à utilização do dinheiro, dos bens e dos serviços do governo municipal nas batalhas eleitorais" (LEAL, 1984, p. 32).

Consoante, Almeida (2020) pontua que o "Estado passa a ser um instrumento pelo qual interesses privados se conformam e se materializam", ainda que na aparência seja ele que se responsabiliza pela coisa pública e pela efetivação do bem comum. Nesse contexto,

\footnotetext{
${ }^{5}$ Para fins desse estudo utiliza-se o conceito de coronelismo no âmbito das políticas locais, por entender que as discussões entre o que seria "coronelismo" e "neocoronelismo", bem como as diferenças entre eles é um debate extenso e que ensejaria estudos mais profundos.
} 
independente de quem seja o chefe municipal, o elemento mais importante é a figura do "coronel”, que comanda lote considerável de votos de cabresto, cuja força eleitoral emprestalhe prestígio político. Esse prestígio para aqueles que lhes agrada, o que seria então o chamado filhotismo.

Aqui percebe-se a importância do voto de cabresto para formação desse fenômeno, em especial na sua origem. Assim, o falseamento de voto é a fraude reiterada dos votos, de acordo com os interesses da política local (LEAL, 1984). Na contemporaneidade, isso ganha outra conformação, mas os interesses privados encobertos pelo manto do Estado ainda agem de maneira a ter como consequência o última categoria a ser mencionada pelo autor, qual seja, desorganização dos serviços públicos locais. O jogo de favores e a ineficiência do Estado em cumprir com seu papel, estando, inclusive, corroborando com esse sistema coronelista tem reflexos até os tempos atuais. $\mathrm{O}$ voto não parece ser tão de cabresto, mas ainda existe troca de favores e cargos por votos. A figura do "coronel" ainda permite a fundação de um Estado fora do Estado, com políticas próprias, e ainda que tal figura não exista, a política coronelista se faz presente.

Por derradeiro, nota-se que os elementos tratados nessa seção, ainda que distantes entre si, alinham-se ao contexto histórico e político que é tratado no filme analisado neste artigo, bem como relacionam-se com as questões atinentes ao pluralismo jurídico exposto na seção anterior. Assim, os diálogos estabelecidos entre os marcos teóricos das últimas seções norteiam a análise do filme Bacurau (2019) que será realizada a seguir.

\section{BACURAU: COMO OS FENÔMENOS SOCIOJURÍDICOS PODEM SE MANIFESTAR ATRAVÉS DA ARTE}

Os estudos sobre Direito e Cinema têm sido instrumento importante para expor e denunciar fenômenos sociojurídicos que devem ter atenção da academia e profissionais do Direito. O cinema nacional vem ganhando cada vez mais espaço com a produção de filmes e documentários que denunciam situações de violência no país, concentrando-se em retratar as mazelas da sociedade brasileira, sendo cada vez mais reconhecida a qualidade das produções no cenário internacional. Foi o que ocorreu com o filme "Bacurau" de 2019, dirigido por Kleber Mendonça Filho, e premiado no Festival de Cannes.

“Se for, vá na paz". Essa é a mensagem da placa que indica os 17 quilômetros até o povoado de Bacurau. O filme retrata a realidade do pequeno município de Bacurau, uma 
cidade no interior de Pernambuco, marcada pelo abandono de políticas públicas, com um povo unido, perspicaz e que resiste às mais diversas adversidades. A cidade é eleita por um grupo de estrangeiros, de origem estadunidense e europeia que perpetuam uma ideologia de supremacia branca, evidenciando uma hierarquia do norte global, em relação ao sul. Dentro deste cenário, o grupo conta com o apoio de dois brasileiros do sul e sudeste que se identificam com o grupo de extermínio. O grupo, por sua vez, vê os brasileiros do sul como subalternos, assim como os do norte e nordeste, visto que seguem sendo latino-americanos e considerados "não-brancos".

O enredo filme é surpreendente e revela a onda conservadora que perpassa por todo o globo e crava raízes na América Latina, em especial em razão do contexto político do Brasil na época e da disseminação de um discurso de hierarquia social que separa norte e sul global, assim como norte/nordeste de sul/sudeste brasileiro. Além disso, o filme abarca uma série de questões como situações de pluralismo jurídico e a presença da necropolítica, do neocolonialismo e das políticas coronelistas na cidade de Bacurau.

Desse modo, a fim de facilitar a análise do filme e assim responder a pergunta central deste estudo, dividiremos esta seção em a) Análise do filme à luz do pluralismo jurídico e b) Análise do filme à luz da necropolítica, neocolonialismo e políticas locais coronelistas.

\section{a) Análise do filme à luz do pluralismo jurídico}

Em Bacurau é marcante a coexistência de mais de uma ordem jurídica, ao considerarmos a realidade do povo que lá habita. É perceptível nas ações práticas de seus habitantes uma dissintonia com as regras ditas "legais", pois as ações práticas que coordenam a vida social do local são diversas e funcionam como resistência aos mandamentos e omissões do governo. Mas, para além disso, são aceitas pelos moradores como regras. Assim, verificamos a existências das três categorias em Bacurau: normas jurídicas, sociais e ideológicas.

As normas estatais podem ser verificadas em alguns pontos do filme, mesmo que não sejam o principal elemento caracterizador da comunidade, devido a sua aceitação e registro formal são utilizadas pelos personagens. Uma delas é vista na campanha eleitoral executada durante o período que o filme, juntamente com o direito à voto da população. $\mathrm{O}$ filme retrata a tentativa de reeleição de Tony Junior, prefeito de Serra Verde, município onde se localiza o povoado de Bacurau, e todos esses atos, de campanha e comunicação com a população, 
demonstram similaridade com o direito estatal e seu cumprimento. Em uma de suas visitas à comunidade, Tony resolve levar uma das prostitutas para lhe servir, ela diz que o tratamento que recebeu da última vez não foi cordial, nesse momento o prefeito é interceptado e lembrado que "puta também vota".

As normas sociais também estão presentes no aceite do uso de psicotrópicos pelo vilarejo, Aquino e Lopes (2020, p. 270) ao analisarem o filme pontuam:

O uso de psicotrópicos, por sua vez, se faz obrigatório no distrito. É através deles
que a população alicerça a sua base para resistir e rebelar-se fora do contexto
autoritário em que se encontram. Produzem-nos com ervas locais, plantadas pelos
próprios moradores, e os bacurauenses que chegam ao povoado são obrigados a
ingeri-los. Na vitória contra os americanos, além da efetiva organização dos
moradores, as substâncias psicoativas mostram-se de suma importância para
encorajar a população no ato de sua defesa: em apenas uma noite, conseguem
planejar e executar com êxito o ataque bem-sucedido, em detrimento aos
americanos que há dias já se preparavam para tal.

No início do filme, quando o caminhão pipa que abastece a comunidade se dirige a ela, Lunga, interpretado por Silvero Pereira, aparece como foragido e com promessa de recompensa em um anúncio que passa no dispositivo visual do veículo. Nesse momento, o motorista e Sandra, que está indo ao enterro de Carmelita, comentam sobre ele e ambos os personagens já demonstram afeto pelo cangaceiro moderno e concordam que de nenhuma maneira o entregariam às autoridades. No decorrer do longa, a simpatia da comunidade local por ele é melhor explorada, pois nasceu e foi criado em Bacurau, onde não é visto como "bandido" como é retratado pelo Estado, mas sim como aliado da comunidade contra os desmandos e vontades do governo.

Com a primeira série de mortes do filme, o povoado recorre ao auxílio de Lunga para promover sua defesa. Nesse aspecto podemos encontrar as normas sociais, pois contrariamente ao esperado das normas estatais, é aceita informalmente sua presença e suas ações, que fazem parte do cotidiano. Assim, para o povo bacurauense é aceitável a presença de Lunga e sua proteção. Do mesmo modo, as mortes e execuções promovidas pelos cidadãos de Bacurau é naturalizada: o personagem Acácio, conhecido como "Pacote", matador de aluguel, também convive sem represálias no povoado, inclusive entre os moradores, que são munidos de internet e celulares, onde circula um vídeo da série de mortes realizadas por Acácio.

A morte, os crimes e a justiça são parte do enredo de Bacurau. Em certa cena, ao final do filme, aparece um carro de polícia velho e baleado, neste momento é comentado que em 
Bacurau não tem polícia, o que se confirma pela própria organização da comunidade para sua defesa. A justiça então, é realizada pelo próprio povo do distrito, seja pelo aceite das mortes promovidas por seus similares na primeira metade do filme (Lunga e Acácio), ou pelo massacre conjunto promovido pelos moradores como defesa à tentativa de caça pelos americanos. Nesse aspecto, após os americanos iniciarem uma série de mortes e promoverem um ataque ao vilarejo, os bacurauenses se unem para revidar e, ao final, conseguem executar todos os forasteiros exceto seu comandante, que é capturado e enterrado vivo em um túnel utilizado pelos moradores como mecanismo de defesa.

Por fim, as normas ideológicas também são identificáveis na película, verifica-se que em Bacurau os moradores convivem aparentemente sem tabus, o sexo é retratado normalmente, as prostitutas convivem na cidade com os demais moradores sem julgamento moral. O nudismo também é abordado, em uma das cenas os moradores cuidam nus de suas plantas e realizam tarefas domésticas sem preocupação com roupas. O banho, mostrado logo no início do filme, é em chuveiro coletivo, onde as pessoas se banham sem importância ou incômodo de quem está do seu lado.

Lunga, o "cangaceiro moderno", que auxilia o povoado e é por eles bem querido, em suas vestimentas e construção demonstra dissociação com qualquer gênero, algo que não é lhe imposto ou cobrado pelo povo para ter aceitação.

Quando o prefeito Tony Junior, em sua campanha de reeleição, traz livros velhos, alimentos e remédios, a população separa o que é útil ou não, posteriormente quando são divididos os mantimentos cada um pega o que lhe for útil, utilizando o bom senso e pensando nos demais, a noção de coletividade e comunidade é intensa na película, o que demonstra a ideologia da comunidade de proteção e aceitação.

\section{b) Análise do filme à luz da necropolítica, neocolonialismo e políticas locais coronelistas}

Nota-se que, no filme, a cidade de Bacurau tem seu abastecimento de água cortado, ficam sem acesso a internet, tendo qualquer meio de comunicação restringido. As políticas públicas são realizadas a partir de trocas e uma sistemática de exploração de uma política coronelista, em que o prefeito da cidade acaba, inclusive, por querer praticamente vender o povo de Bacurau aos estrangeiros mal intencionados. Assim, percebe-se técnicas de destruição do inimigo ou da terra arrasada, apresentados no item dois do presente artigo, o que 
permite completa apropriação dos recursos daquela terra e desumanização daquele povo. A necropolítica e o necropoder marcam diversas cenas do filme, visto que, quase que literalmente, o grupo de extermínio estadunidense escolhe quem vai viver e quem vai morrer em Bacurau.

Ademais, como se trata de um país do sul global, as colônias acabam sendo zonas em guerra e desordem, logo tanto o controle e garantias de ordem judicial podem ser facilmente suspensas. Não é sem motivo que os estadunidenses que escolheram Bacurau como campo do seu jogo de morte, estabeleceram a escolha a partir de critérios racistas. Vê-se que até mesmo os brasileiros da região sul e sudeste, retratados no filme, internalizaram a cultura do colonizador e acreditavam ser superiores aos moradores de Bacurau e foram, durante a película, facilmente assassinados pelo próprio grupo de extermínio que os contratou.

$\mathrm{Na}$ cena em que João e Maria, os brasileiros do sul e sudeste, justificam sua semelhança com os Europeus, dizendo serem mais próximos do grupo de estadunidenses e fazerem parte daquele jogo de morte, os dois viram piada para o grupo que não pestaneja ao escolher a morte do casal.

A mentalidade e ideologia racista serve como pano de fundo de todas as escolhas do grupo de assassinos, inclusive a escolha pela cidade Bacurau, o que revela como as políticas neocolonialistas possuem um viés ideológico que condenam os povos do sul global a reproduzirem também as ideologias de hierarquia social e, assim, manter os privilégios do norte. Desvalorizar a cultura dos sertanejos e do povo de Bacurau é estratégia social e econômica do neocolonialismo, que influencia diretamente até mesmo nas políticas locais.

No caso do nordeste, a região é marcada historicamente por políticas coronelistas em que o povo está submisso a uma figura até mesmo autoritária, em que se deve obediência e requer cuidado. No filme a figura desse "coronel" é a do prefeito da cidade, que manda em toda localidade, mas que tem medo e respeito apenas pelos norte americanos, visto que visualiza neles uma ascensão individual.

A pequena cidade de Bacurau subverte todos os valores perpetuados pelo neocolonialismo e pelas políticas coronelistas de seu prefeito, defendendo-se do grupo de extermínio, em uma legítima defesa, no âmbito das leis da própria cidade, capturando e condenando o grupo estadunidense de acordo com suas próprias regras. Do mesmo modo, a população bacurauense rompe com o pacto do coronealismo, representado pelo prefeito da cidade, que sai de cena humilhado e amarrado num burro. 
Demonstra-se, assim, o potencial revolucionário e a resistência do povo local que não cede às arbitrariedades dos novos colonizadores. Valoriza a cultura e os conhecimentos do sul global, dos brasileiros nordestinos e, mais especificamente, os bacurauenses que, a partir de suas próprias normas, resistem e se defendem das políticas de morte e ou necropolítica em que são submetidos pelo Estado brasileiro e pelas potências econômicas do norte global.

\section{CONSIDERAÇÕES FINAIS}

Se o direito não reflete a realidade social em seu todo, tarefa difícil seria para o cinema traduzir as complexas relações humanas em suas películas. Bacurau, no entanto, consegue captar em sua distopia questões deixadas de lado pelo Estado, como o abandono da população carente da cidade, as mortes não solucionadas por autoridades e o assistencialismo político, fenômenos presentes no vilarejo fictício, mas também em diversos outros locais do país onde as práticas de mandos por políticos locais submete o povo às suas vontades.

Retratar nas telas tais omissões significa utilizar uma lente de aumento em pessoas e situações invisibilizadas pelo Estado. Se Bacurau some do mapa no filme, pela vontade de extermínio de um grupo de estrangeiros, e pelas ações de desleixo de seu prefeito, tantos outros locais somem com a história, pois, sofrem as mesmas sanções por autoridades locais, cada "não" ou ausência, muitas vezes propositais, deixa no esquecimento culturas menores que não resistem como Bacurau resistiu.

Assim, o filme criticamente desvela o desleixo dos governantes com as comunidades mais abastadas, prática comum em todo o país, com a precariedade (ou inexistência) de abastecimento de água, sua falta, a seca, a falta de livros de qualidade para a escola, transporte público e remédios.

Mas, Bacurau não se prende somente a isso, seu ponto chave, é justamente outro, quando revela a capacidade organizacional local e comunitária frente a ausência do Estado. Bacurau possui suas próprias regras sociais e costumeiras, como bem abordado acima, o local é recinto de uma gama heterogênea de pessoas que tem respeitadas suas identidades, como negros, brancos, homossexuais, justiceiros, dentre outros.

A organização e normas existentes em Bacurau representam a manifestação do pluralismo jurídico no longa, em que uma população em um espaço de conflito consegue se guiar pelas suas próprias diretrizes, paralelas ao Estado, que pouco faz pela comunidade. Assim, os bacurauenses, a partir de uma ordem própria, resistem e se defendem das políticas 
de morte e ou necropolítica em que são submetidos pelo Estado brasileiro e pelas potências econômicas do norte global.

\section{REFERÊNCIAS}

ALMEIDA, Juliana Leme Faleiros Silvio. O coronelismo de Victor Nunes Leal e a modernização conservadora: colocações iniciais. Revista de Direito, Viçosa, v. 1, n. 2, p. 0126, 2020. ISSN 2527-0389.

AQUINO, Arthur Nadson Macedo de; LOPES, Pablo Ruan Siqueira. Paradoxo do pluralismo jurídico diante de um Estado autoritário: o voo de bacurau. In: Repensando o jurídico nas interações entre direito e arte. Vol. I. Belo Horizonte: Senso, 2020.

BACURAU. Direção: Leandro Dornelles e Kleber Mendonça Filho. Brasil: CinemaScópio. 2019, 2h12min.

\section{BALLESTRIN, Luciana. Modernidade/Colonialidade sem "Imperialidade"? O Elo} Perdido do Giro Decolonial. In: Dados, vol. 60, n. 2. Rio de Janeiro, abr/jun. 2017.

CARVALHO, Lucas Borges de. Caminhos (e descaminhos) do pluralismo jurídico no Brasil. In: WOLKMER, Antonio Carlos; VERAS NETO, Francisco Q.; LIXA, Ivone M. (Org.). Pluralismo jurídico: os novos caminhos da contemporaneidade. São Paulo: Saraiva, 2013. p. $13-36$

CARVALHO, Rejane Vasconcelos Anciolly. Coronelismo e neocoronelismo: eternização do quadro de análise política do nordeste? Caderno de Estudos Sociais, Recife, v. 3, n. 3, p. 193-206, jul/dez 1987. Disponível em: https://periodicos.fundaj.gov.br/CAD/article/view/1025/745

FOUCAULT, Michel. Nascimento da Biopolítica. Trad. Eduardo Brandão. São Paulo: Martins Fontes, 2008. 
FRANÇA, Mateus Cavalcante de. Quando surge um novo Direito:: o pluralismo jurídico representado no cinema brasileiro. 2018. 114 f. TCC (Graduação) - Curso de Direito, Universidade Federal do Rio Grande do Norte, Natal, 2018.

KONZEN, Lucas Pizzolatto. Norms and space: understanding public space regulation in the tourist city. 336 f. Tese (Doutorado) - Curso de Law and Society, Università Degli Studi di Milano, Milão (Itália), 2013.

LEAL, V. N. Coronelismo, enxada e voto: o município e o regime representativo no Brasil. 7ª ed. São Paulo: Companhia das letras, 1984.

MARTINEZ, Renato de Oliveira. Direito e Cinema no Brasil : perspectivas para um campo de estudo / Renato de Oliveira Martinez; orientador, Luis Carlos Cancellier de Olivo - Florianópolis, SC, 2015. 194 p.

MBEMBE, Achille. Necropolítica: Biopoder, soberania, estado de exceção, política de morte. Trd. Renata Santini. Rio de janeiro: n-1 edições, 2018.

SANTOS, Boaventura de Sousa. Notas sobre a História Jurídico-Social de Pasárgada. Disponível em: http://www.geocities.ws/b3centaurus/livros/s/boavpassar.pdf. Acesso em: 11 de abril de 2021.

SANTOS, Boaventura de Sousa. Uma cartografia simbólica das representações sociais: prolegómenos a uma concepção pós-moderna do Direito. Revista Crítica de Ciências Sociais, Coimbra, v. 1, n. 24, p.139-168, mar. 1988.

SELIGMANN-SILVA, Márcio. Violência e cinema: um olhar sobre o caso brasileiro hoje. Comunicação \& Cultura, n. ${ }^{\circ}$ 5, 2008, pp. 95-108

WOLKMER, Antonio Carlos. Pluralismo jurídico: fundamentos de uma nova cultura no Direito. São Paulo: Alfa Omega, 2001 